Asian Journal of Biotechnology 3 (6): 554-563, 2011

ISSN 1996-0700 / DOI: 10.3923/ajbkr.2011.554.563

(C) 2011 Knowledgia Review, Malaysia

\title{
In vitro Germination and Pollen Conservation of Some Musa Species
}

\author{
${ }^{1}$ Emmanuel Youmbi, ${ }^{1}$ N.J.P. Fonkam, ${ }^{2}$ Kodjo Tomekpe and ${ }^{2}$ Cletus Fonbah \\ ${ }^{1}$ Laboratory of Biotechnology and Environment, Unit of Physiology and Plant Improvement, Department \\ of Plant Biology, Faculty of Science, University of Yaounde 1, P.O. Box 812, Yaounde, Cameroon \\ ${ }^{2}$ African Centre of Research on Banana and Plantain, P.O. Box 832, Douala, Cameroon \\ Corresponding Author: Emmanuel Youmbi, Laboratory of Biotechnology and Environment, Unit of Physiology and \\ Plant Improvement, Department of Plant Biology, Faculty of Science, University of Yaounde 1, P.O. Box 812, Yaounde, \\ Cameroon
}

\begin{abstract}
The yield of banana and plantain which is an important food is affected especially by black leaf streak disease. Pollen from resistant wild types is used by conventional breeding to create new hybrids resistant to black leaf streak disease. A strategy of pollen genetic resource preservation and storage is necessary for this breeding. The main objective of this study was to optimize the conditions for in vitro germination, conservation and storage of pollen from three banana diploids (Musa acuminata). Pollen grains used in this study were collected from Njombe and Ekona banana collections. The basal media used for in vitro culture were those of Heslop-Harrison and Brewbaker and Kwack. Different temperature and $\mathrm{pH}$ values tested allowed for the evaluation of germination rates. Pollen were desiccated and stored in a freezer $\left(-20^{\circ} \mathrm{C}\right)$ and in a refrigerator $\left(+10^{\circ} \mathrm{C}\right)$. The results obtained showed that the basal medium of Heslop-Harrison supplemented with 5\% sucrose allowed to obtain optimum pollen germination rate. The optimum temperature was $30^{\circ} \mathrm{C}$ and the optimum $\mathrm{pH}$ values were 6.5 for Calcutta and 6.8 for M53 and Zebrina. The pollen grains of the three varieties can be conserved freshly in the refrigerator at $+10^{\circ} \mathrm{C}$ for at least two months. These results are very important for banana and plantain breeding programs because the conditions of pollen storage for the three varieties are well established and permit genetic material sharing and diffusion between different banana research centers.
\end{abstract}

Key words: Musa acuminata, male gametophyte, in vitro germination, dehydration, storage

\section{INTRODUCTION}

Genetic improvement of banana and plantain in the world is led by several researchers from CIRAD (Centre de Coopération Internationale en Recherche Agronomique pour le Développement) in France, FHIA (Fundacion Hondurena de Investigacion Agricola) in Honduras, IITA (Institute of Tropical Agriculture) in Nigeria, CARBAP (Centre Africain de Recherches sur Bananiers et Plantains) in Cameroon and EMBRAPA-CNPMF (Centro National de Pesquisa de Mandioca e Fruticultura Tropical) in Brazil (Bakry et al., 2009). At the international level, two different radical strategies for creating varieties are used: the first is aimed at obtaining tetraploid varieties while the second is to obtain triploid varieties. Despite the high sterility in banana, some triploid varieties produce rare diploid parental gametes (female gamete $(n=x=33)$, which after fertilization by a pollen of a diploid variety, will be the source of seeds containing tetraploid embryo able to 
germinate. The strategy of genetic improvement consists in associating the complete genome of a cultivated variety with that of a variety with haploid parental genome having resistance to pests and diseases. The investigations of back cross with the tetraploids and other improved diploids have never led to obtain the interesting triploid hybrids (due probably to female nucleus bursting during tetraploid meiosis).

CIRAD has developed an original strategy for improvement based on the creation of triploids from naturally improved planting material. After selection, the best diploids are treated with colchicines to induce the formation of auto or allotetraploids. Thereafter, these tetraploid and diploids are crossed with the aim of producing triploid plants. All these crossings require pollen (Bakry et al., 2007).

Pollen conservation is advantageous since it can be stored for a long period without losing its viability (Hanna and Towill, 1995). In this way, transportation and diffusion of pollen in view of carrying out hybridization between plants dispersed in space and time at flowering will be facilitated (Charrier, 1990). But pollen germination and viability depend on many factors involving the culture medium composition (Prom, 2007; Mahmoodzadeh and Bemani, 2008) and air pollution condition (Chehregani et al., 2004). Studies on pollen preservation and viability are important for understanding the reproductive performances of species and also to lead improvement programmes with success (Dafni and Firmage, 2000). Few pollen banks exist till date mainly on ligneous tropical forest trees (Charrier, 1990). Wild plants are often considered as genes bank useful to solve problems in cultivated species which are often sprayed by insecticides that significantly affect the viability of pollen (Mehri et al., 2007). This research was therefore aimed at studying the optimal conditions of in vitro germination and preservation of pollen of three diploid banana varieties.

\section{MATERIALS AND METHODS}

Pollen of three diploid banana (Calcuta 4, M 53 and Zebrina) used in this work were collected from CARBAP's collection in Njombé (4 $35^{\prime}$ latitude North and $9^{\circ} 39^{\prime}$ longitude East) and Ekona $\left(4^{\circ} 14^{\prime} 00^{\prime \prime} \mathrm{N}\right.$ latitude North and $9^{\circ} 20^{\prime} 04^{\prime \prime}$ longitude East) located, respectively in the Littoral and South-West regions of Cameroon, Centre Africa, in 2008. Calcuta 4 and Zebrina are wild varieties originating from Southeast Asia, M53 is a hybrid created in Jamaica and improved in Guadeloupe by CIRAD-FLHOR. The pollen of these bananas are needed in genetic improvement because of their resistance to black leaf streak disease and their tolerance to nematodes.

Mature male buds were harvested from the collection and wrapped in polyethylene bags to prevent dehydration during transportation. In the laboratory, with the aid of spatula, the anthers were opened and the pollen deposited into small glass bottles. This operation does not leave the pollen in the terminal phase. The pollen is independent of environmental conditions around it and can be extracted without damage during the two or three last days before the breaking off of the anther (Picard, 1995).

The pollen grains extracted from anthers were divided into three lots:

- Lot 1 was made of pollens subjected to dehydration in a desiccator before storage in a

- Deep freezer at $-20^{\circ} \mathrm{C}$

- In a refrigerator at $+10^{\circ} \mathrm{C}$

- Lot 2 was made of fresh pollens which were directly stored in a

- Deep freezer at $-20^{\circ} \mathrm{C}$

- Refrigerator at $+10^{\circ} \mathrm{C}$

- Lot 3 was made of fresh pollen subjected to different in vitro germination tests 
Culture media, saccharose concentration, temperature and pH: Determination of a suitable medium for in vitro pollen germination was carried out using the classical media of Brewbaker and Kwack (1963) and that of Heslop-Harrison (1979) with and without the addition of $1 \%$ agar. Different sucrose concentrations $(0,5,10,15,20,25,30$ and 35$)$ were used to determine which was more favourable for germination. Also, the influence of temperature $\left(25,30,35\right.$ and $\left.40^{\circ} \mathrm{C}\right)$ as well as the influence of $\mathrm{pH}(5 ; 5.3 ; 5.6 ; 5.9,6.2 ; 6.5 ; 6.8$ and 7.1$)$, were investigated.

The two media were mounted on slides and spread with pollen grains using magnifying glass. These slides were stored in Petri-dishes under saturated atmosphere (the saturation of the atmosphere was obtained by adding water on Watman paper). These Petri-dishes were incubated at a constant temperature of $30^{\circ} \mathrm{C}$ for $24 \mathrm{~h}$. Slides removed from the incubator were stained using the method described by Alexander (1969). A Photon microscope was used to count the number of germinated pollen. Germinated pollens are those found with tube length longer than half the pollen diameter (Youmbi et al., 1998). Germination data were collected on a sample of about 400 pollen grains on three replications.

Germination rates were used to determine the best culture medium, the optimum saccharose concentration and the optimum temperature and $\mathrm{pH}$.

The germination ability was studied. The fresh pollens were dehydrated using desiccators. They were then removed after 3,6 and 9 days and kept in a freezer at $-20^{\circ} \mathrm{C}$ and in a refrigerator at $+10^{\circ} \mathrm{C}$. Samples were taken at 5 days interval for germination test.

Method of conservation: Fresh pollens were placed into a desiccator and four times of dehydration $\left(\mathrm{T}_{1}, \mathrm{~T}_{2}, \mathrm{~T}_{3}\right.$, and $\left.\mathrm{T}_{4}\right)$ were tested. $\mathrm{T}_{1}$ to $\mathrm{T}_{4}$ represents the time as week 1 to 4 , respectively when the pollen was removed from the desiccator before conservation. The index number shows the period in weeks of pollen dehydration.

The content of each small glass bottle removed from the desiccator was divided into two parts. Twelve of these glass bottles were transferred into a freezer at $-20^{\circ} \mathrm{C}$ and the other 12 into a refrigerator at $+10^{\circ} \mathrm{C}$. Every 30 days, the pollens were removed and subjected to in vitro germination test. These regular tests on different stocks (controlled and preserved) allowed the observation of pollen germination (Cerceau-Larrival and Challe, 1986; Cauneau-Pigot, 1988).

Statistical analysis: Data collected were analysed using the computer software STAT-ITCF and the means separations were performed using the Newmans-Keuls post test at $5 \%$ level of significance.

\section{RESULTS}

Effect of base medium and sucrose concentration: Pollen germinated on both Brewbakner and Kwack $(\mathrm{BK})$ and Heslop Harrison $(\mathrm{HH})$ media. But pollen did not germinate at all sucrose concentrations (Fig. 1, 2). On both media, the germination rate was zero in the absence of saccharose. The germination rate was higher on $\mathrm{HH}$ medium than on $\mathrm{BK}$ medium. On $\mathrm{HH}$, the optimum germination rate was $44.18 \%$ at $5 \%$ saccharose concentration while on BK medium, it was $8.15 \%$ at $15 \%$ saccharose concentration. The germination rate decreased to $0 \%$ at 20 and 30 saccharose concentrations, respectively on BK and HH media (Fig. 1).

For M 53 hybrid, at 0\% saccharose concentration, the germination rate was $1.15 \%$ on Heslop Harrison (HH) medium while it was zero on Brewbakner and Kwack (BK) medium. The optimum germination rates were $46.31 \%$ at $5 \%$ saccharose concentration and $28.03 \%$ at $10 \%$ saccharose 


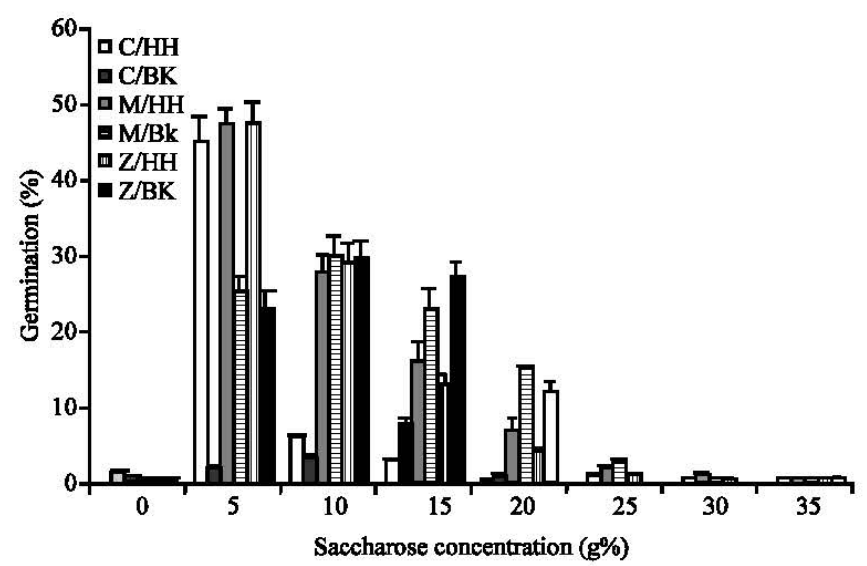

Fig. 1: Influence of Brewbaker and $\mathrm{Kw}$ ack (BK), Heslop-Harrison ( $\mathrm{HH}$ ) based media and the sucrose concentration on the germination of pollen in three diploid bananas (Musa acuminata)

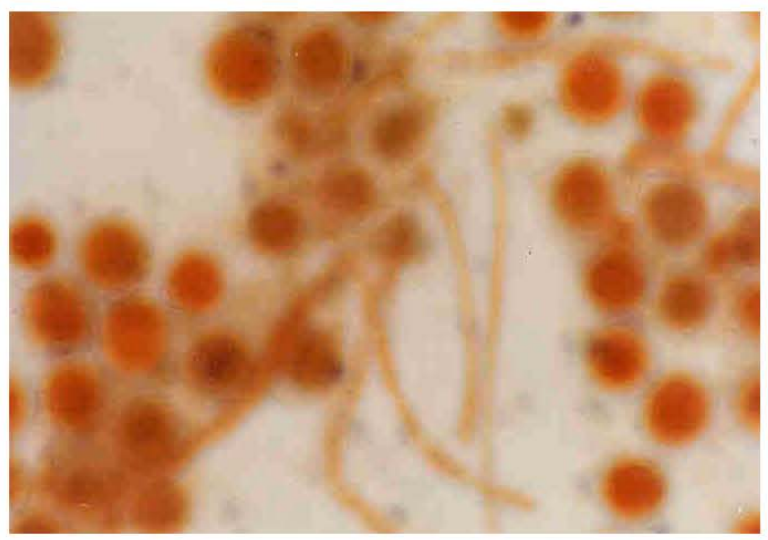

Fig. 2: Germination of fresh pollen of Calcutta 4 on Heslop-Harrison medium supplemented with $5 \%$ sucrose at $\mathrm{pH} 6.5$

concentration on Heslop Harrison (HH) and on Brewbakner and Kwack (BK) media, respectively. On both media, the germination became zero at 35\% saccharose concentration (Fig. 1).

Pollen grains of Zebrina varieties equally germinated on the two base media. On Heslop Harrison $(\mathrm{HH})$ medium, the germination rate was zero at $0 \%$ saccharose concentration. The optimum germination rate was 46.61 at $5 \%$ saccharose concentration (Fig. 1, 3). The germination decreased to zero at 30\% saccharose concentration. On Brewbakner and Kwack (BK) medium, pollen grains of Zebrina germinated with low percentage $(0.38 \%)$ at $0 \%$ saccharose concentration. The optimum germination rate (27.73) was obtained at $10 \%$ sucrose concentration. The germination rate decreased to zero at $25 \%$ saccharose concentration.

Statistical analysis showed that the medium-concentration interaction was highly significant $(\alpha=0.001)$ with all the pollens. The Heslop Harrison $(\mathrm{HH})$ medium supplemented with $5 \%$ sucrose concentration allowed higher mean percentage of germination (Fig. 1). Germination rates of the three banana varieties were significantly different $(\alpha=0.01)$ on this combined media. 


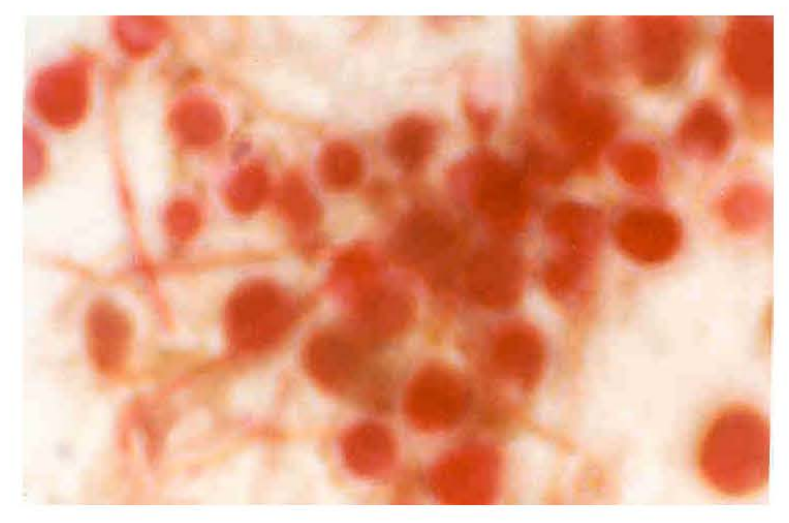

Fig. 3: Germination of fresh pollen of M 53 on Heslop-Harrison medium supplemented with 5\% sucrose at $\mathrm{pH}=6.8$

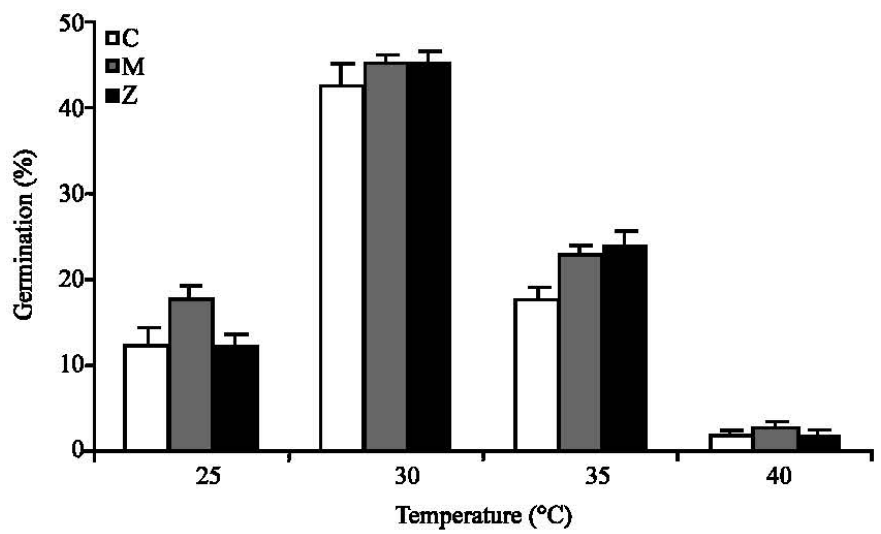

Fig. 4: Influence of temperature on the germination of pollen from three diploid bananas (Musa acuminata)

Pollen grains of the three banana varieties germinated at all the temperatures. The germination rates were low $(12.77,17.92$ and $13.06 \%)$ at low temperature $\left(25^{\circ} \mathrm{C}\right)$ for Calcuta 4 , M53 and Zebrina, respectively. The optimum germination rates: $44.18,46.31$ and $46.61 \%$ were obtained at $30^{\circ} \mathrm{C}$ for Calcuta 4, M53 and Zebrina, respectively. Above this value, the mean percentage dropped with increasing temperature and became the lowest $(0.97,4.36$ and $3.41 \%)$ for Calcuta 4, M53 and Zebrina, respectively at $40^{\circ} \mathrm{C}$ (Fig. 4).

Statistical analysis showed that there was a significant difference $(\alpha=0.001)$ between the different temperature levels studied. The best temperature recorded w as $30^{\circ} \mathrm{C}$ (Fig. 3). However, the percentages of pollen germination of the three bananas under this best temperature were significantly different $(\alpha=0.05)$. Two groups of similar characteristics were distinguished: M53 and Zebrina on one side and Calcuta 4 on the other side.

The in vitro pollen germination was influenced by $\mathrm{pH}$. The germination rates were the lowest (5.12, 7.5 and $0.89 \%$ ) at $\mathrm{pH} 5$ for Calcuta 4, M53 and Zebrina, respectively. These germination rates increased with increasing $\mathrm{pH}$ values, reaching the maximum values of $43.2 \%$ at $\mathrm{pH} 6.5$ for 


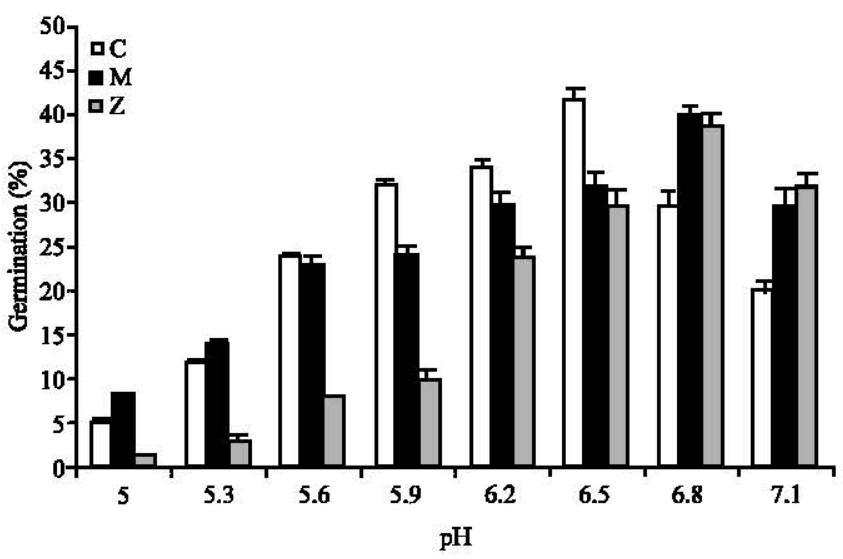

Fig. 5: Effect of $\mathrm{pH}$ on pollen germination of three diploid bananas (Musa acuminata)

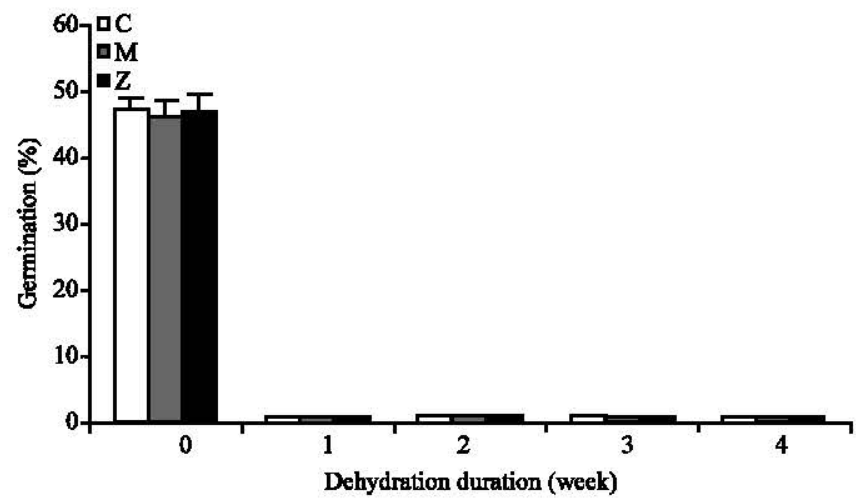

Fig. 6: Influence of the duration in dehydration on pollen germination of three diploid bananas (Musa acuminata)

Calcuta 4 and 42.48 and $41.31 \%$ at pH 6.8 for M53 and Zebrina, respectively. Beyond these optimal $\mathrm{pH}$ values, the germination rates decreased and became $18.41,31.17$ and $32.53 \%$ at $\mathrm{pH} 7.1$ for Calcuta 4, M53 and Zebrina, respectively (Fig. 5).

Statistical analysis showed a highly significant difference $(\alpha=0.001)$ between the different $\mathrm{pH}$ values studied. The favourable $\mathrm{pH}$ values were 6.5 for Calcuta 4 and 6.8 for M53 and Zebrina (Fig. 5).

Preservation and storage: The pollen grains of the three banana varieties did not germinate after being kept in the desiccator for less than a week. Only the control (fresh pollen) did have optimal germination rates. The mean germination percentage was: $44.18,46.31$ and $46.61 \%$ for Calcuta 4, M 53 and Zebrina, respectively. The statistical analysis showed that the fresh status of banana pollen was highly significantly different $(\alpha=0.001)$ to the dried status (Fig. 6 ).

The germination rates of fresh pollen grains (before storage) were $44.18,46.31$ and $46.61 \%$ for Calcuta 4, M 53 and Zebrina, respectively. After 30 days of storage at $-20^{\circ} \mathrm{C}$, these germination rates decreased rapidly to become 0.78 and $0.76 \%$, respectively for Calcuta 4 and M 53. After 60 days of storage at $-20^{\circ} \mathrm{C}$, the germination rate of pollen grains of Zebrina decreased to $0.30 \%$ (Fig. 7). 


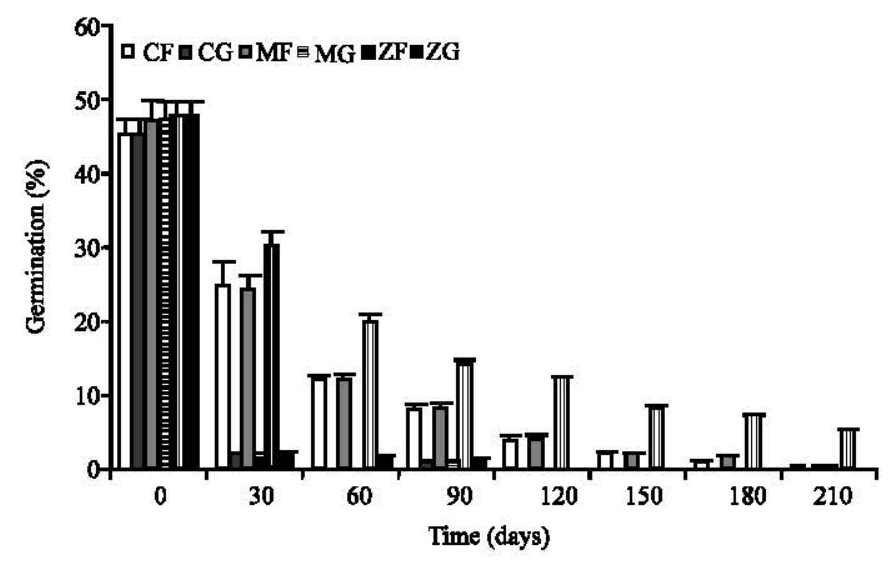

Fig. 7: Variation in pollen germination capacity of three diploid banana (Musa acuminata) stored in the refrigerator $\left(+10^{\circ} \mathrm{C}\right)$ and deep freezer $\left(-20^{\circ} \mathrm{C}\right)$. F: Refrigerator, G: Deep freezer

When stored at $+10^{\circ} \mathrm{C}$, the germination rates decreased more weakly and became $0.48 \%$ for Calcuta and $0.75 \%$ for M 53 after 180 days of storage. For Zebrina the germination rates decreased to $4.73 \%$ after 210 days of storage at $+10^{\circ} \mathrm{C}$ (Fig. 7 ).

Statistical analysis showed that there was a highly significance difference between the different places of storage $(\alpha=0.001)$. The best place of storage was the refrigerator $\left(+10^{\circ} \mathrm{C}\right)$ for all the pollens of the three varieties. The storage duration was equally highly significantly different $(\alpha=0.001)$. During storage in the refrigerator, two groups with the same characteristics were distinguished: Calcuta 4 and M 53 in one group and Zebrina in the other group (Fig. 7).

\section{DISCUSSION}

The pollen grains of these bananas germinated on the two growth media used but the highest germination percentage was obtained on the Heslop-Harrison medium containing 5\% sucrose. According to the classification made by Brewbaker (1967), banana pollen grains are binuclear. Binuclear pollen grains germinate easily on BK medium. These observations are contrary to those mentioned by Youmbi et al. (1998) who found that at high concentration of sucrose (25-30\%) in the media, HH medium was better than BK for the germination of the pollen of Dacryodes edulis. The optimum germination rate in all the cases was less than 50\%. This might be due to plant species, harvesting conditions and transport to the laboratory. The distance between the place of harvest (Ekona, Njombe) and the laboratory (Yaounde) was far away (about $320 \mathrm{~km}$ ). In the course of transportation, the pollens were probably subjected to dehydration, which caused in the membrane the alteration of glycoproteins, glycolipids, pigments and ions favourable for germination (Cerceau-Larrival et al., 1995). The different behaviours of pollen grains observed on the base media were probably due to biochemical and chemical nature of exine which is a component of pollen grain wall (Cerceau-Larrival et al., 1995) or to the specificity of pollen grains of each banana cultivar. The preference of the Heslop-Harrison medium by the pollens of the three banana cultivars compared to the Brewbaker and Kwack medium was observed for allergenic pollens, characterized by the presence of micro canals (Cerceau-Larrival and Challe, 1986). This preference for Heslop-Harrison medium could be due to its higher concentration of boric acid compared to that of Brewbaker and Kwack. 
Sugar equally played an important role on pollen grains germination. Saccharose played an osmotic role in the culture media. In addition, it is used as a source of nutrition for pollen tube growth (Loguercio, 2002; Baloch et al., 2001). The highest germination rates were obtained for three cultivars with $5 \%$ saccharose on Heslop-Harrison medium. These results corroborated with that obtained in studying in vitro germination of Streptocarpus pollen. The optimum saccharose concentration (5\%) was different to that found (10\%) while studying in vitro pollen germination of Betula verrucosa (Bocquel, 1995). It is also contrary to the observations on in vitro pollen germination of Dacryodes edulis where the optimum germination rate was obtained on Brewbaker and Kwack medium supplemented with $20 \%$ saccharose (Youmbi et al., 1998). This sugar became unnecessary at higher concentrations on which bursting of pollen tubes were observed. Yang and Endo (2005) observed bursting of pollen tubes of Brassica napus L. Five hours after incubation on Hodgkin medium supplemented with $10 \%$ sucrose. The bursting of pollen tubes can be reduced on adding polyethylene glycol in the culture medium (Yang and Endo, 2005) or reducing sucrose concentration.

The germination of pollens of the three banana varieties was influenced by temperature. Their optimum germination was recorded at $30^{\circ} \mathrm{C}$; a similar value obtained for germination of pollens of Dacryodes edulis (Youmbi et al., 1998). Baloch et al. (2000) also found that the pollen grains of cotton are vulnerable above $35^{\circ} \mathrm{C}$.

Pollen germination in this study was also influenced by $\mathrm{pH}$. The optimum germination values were 6.5 for Calcuta 4 and 6.8 for M53 and Zebrina. These values were slightly different from those obtained by Tamnet et al. (2011) for germination of Senna spectabilis (5.6). For Dacryodes edulis (Youmbi et al., 1998), optimum germination was obtained on Brewbaker medium at pH 5.3. pH is an important factor that triggers pollen germination and its optimal value is a function of the species (Goddard and Mathews, 1981).

The results showed that only fresh pollens were better preserved. The dehydrated pollen lost their germinative ability within a week. This observation is similar to that of Tamnet et al. (2011), who showed that the pollen of Senna spectabilis lost their germination ability from one week to other, after dehydration. The absence of germination could be due to dehydration threshold being exceeded. The germination rates of banana pollen grain decreased with increasing desiccation and storage times. Similar results demonstrating that pollen viability was highly dependent on temperature and relative humidity have been published earlier by Baloch et al. (2000). In fact, pollen characterized by a fragile exine could quickly lose plasmic membrane permeability, with a speedy dehydration (Digonnet-Kerhoas and Gay, 1990). Physiological considerations are also important during the course of pollen storage (Kwon et al., 2005). The desiccation must be done in a limited time (one or two hours) and must not exceed a critical threshold: $2 \%$ for pine, $4 \%$ for coconut tree (Charrier, 1990). During dehydration, some cytoplasmic materials would be lost when the membrane phospholipids are changing from gel phase to crystal liquid phase. The loss of pollen viability is probably attributed to the gel crystal liquid phase transition (Crowe et al., 1989).

Storage in the refrigerator $\left(+10^{\circ} \mathrm{C}\right)$ had the best results compared to deep freezer $\left(-20^{\circ} \mathrm{C}\right)$. Storage in the freezer did not allow conservation of germinative ability during 30 days for Calcuta 4 and M 53 and 60 days for Zebrina. The water contents must be controlled to determine those that, in concordance with the storage temperature will give the best results. Excess humidity has been found to reduce the germination rate (Kwon et al., 2005). At low temperature, water in pollen crystallizes and eventually leads to pollen alteration. This result is contrary to the observations which showed that longevity of freeze-dried pollen increased when stored in the freezer at $-20^{\circ} \mathrm{C}$ 
(Charrier, 1990); in fact, freeze-dried pollen of Betula sp. germinated well after storage at $-20^{\circ} \mathrm{C}$, those of Prunus persica and Medicago sativa germinated after 9 and 11 years, respectively. Only pollen stored in the refrigerator $\left(+10^{\circ} \mathrm{C}\right)$ preserved their germination capacity for 180 days (Calcuta 4 and M 53) and 210 days (Zebrina). A reduction of almost half of the germination rate was observed after the first 30 days of storage.

For successful hybridizations with stored pollens, it will be necessary to carry out the pollination at least 60 days after collecting the pollen for Calcuta 4 and M 53 and 120 days for Zebrina when the percentage of germination is still higher than $10 \%$.

\section{CONCLUSION}

These results show that more than $10 \%$ of pollen of the studied varieties can germinate even after 60 days (more than 2 months) of conservation. This is quite important and fundamental for the different banana and plantain breeding programmes as pollen can be conserved and diffused for hybridization in the different Research Centers.

\section{REFERENCES}

Alexander, M.P., 1969. Differential staining of aborted and non aborted pollen. Biotec. Histochem., 44: 117-122.

Bakry, F., N.P. de la Reberdiere, S. Pichot and C. Jenny, 2007. In liquid medium colchicine treatment induces non chimerical doubled-diploids in a wide range of mono- and interspecific diploid banana clones. Fruits, 62: 3-12.

Bakry, F., F. Carreel, C. Jenny and J.P. Horry, 2009. Genetic Improvement of Babana. In: Breeding Plantation Tree Crops: Tropical Species, Jain, S.M. and P.M. Priyadarshan (Eds.). Springer, New York, pp: 3-50.

Baloch, M.J., A.R. Lakho, R. Rind and H. Bhutto, 2000. Screening of cotton genotypes for heat tolerance via in vitro gametophytic selection technique. Pak. J. Biol. Sci., 3: 2037-2038.

Baloch, M.J., A.R. Lakho, H. Bhutto and M.Y. Solangi, 2001. Impact of sucrose concentrations on in vitro pollen germination of Okra, Hibiscus esculentus. Pak. J. Biol. Sci., 4: 402-403.

Bocquel, C., 1995. Technologie de conservation et de stockage du pollen de Bouleau (Betula verrucosa). Germination in vitro de pollen frais et pollue: Action des facteurs environnementaux. Grana, 34: 413-420.

Brewbaker, J.L. and B.H. Kwack, 1963. The essential role of calcium ion in pollen germination and pollen tube growth. Am. J. Bot., 50: 859-865.

Brewbaker, J.L., 1967. The distribution and phylogenetic significance of binucleate and trinucleate pollen grain in Angiosperms. Am. J. Bot., 54: 1069-1083.

Cauneau-Pigot, A., 1988. Interest from the cold for the conservation and storage of pollen allergies (Dactylis glomerata L.). Control viability by in vitro tests and inorganic elements detected by X-ray spectrometry selection of anergy. Ann. Sci. Nat. Bot., 13: 153-162.

Cerceau-Larrival M.T., Y. Delange, E. Youmbi, L. Derouet, A.M. Verhille and M.C. CarbonnierJarreau, 1995. Contribution to the preservation of genetic male patrimoine living plant collections of the Museum National d'Histoire Naturelle, Paris. Grana, 34: 371-407.

Cerceau-Larrival, M.T. and J. Challe, 1986. Biopalynology and Maintenance of Germination Capacity of Stored Pollen in some Angiosperm families. In: Pollen and Spores: Form and Function. Blackmore, S. and I.K. Ferguson (Ed.). Academic Press, London, pp: 151-164.

Charrier, A., 1990. Pollen et resources genetiques. Soc. Fr., Actual. Bot., 173: 101-104. 
Chehregani, A.H., A. Majde, M. Moin, M. Golami, S.M. Shariatzadeh and F. Mohsenzae, 2004. Effect of air pollution on some cytogenetic characteristics, structure, viability and proteins of Zinnia elegans pollen grains. Pak. J. Biol. Sci., 7: 118-122.

Crowe, J.H., F.A. Hoekstra and L.M. Crowe, 1989. Membrane phase transitions are responsible for imbibitional damage in dry pollen. Proc. Natl. Acad. Sci. USA., 86: 520-523.

Dafni, A. and D. Firmage, 2000. Pollen viability and longevity: Practical, ecological, evolutionary implications. Plant System. Evol., 222: 113-132.

Digonnet-Kerhoas, S.C. and G. Gay, 1990. Qualite du pollen: Definition et estimation. Bull. Soc. bot. Fr.,137, Actual. bot., 137: 97-100.

Goddard, R.E. and F.R. Mathews, 1981. Pollen Testing. In: Pollen Management Handbook, Franklin, E.C. (Ed.). Agriculture Handbook 587. USDA Forest. Service, Washington, DC., pp: 40-43.

Hanna, W.W. and L.E. Towill, 1995. Long-Term Pollen Storage. In: Plant Breeding Reviews, Janick, J. (Ed.). Vol. 13, John Wiley and Sons, Inc., Oxford, UK., pp: 179-207.

Heslop-Harrison, J., 1979. Aspect of the structure cytochemistry and germination of the pollen of rye (Secale cereale L.). Ann., 44: 2-65.

Kwon, S.W., M.J. Jaskani, B.R. Ko and J.L. Cho, 2005. Collection, germination and storage of watermelon (Citrullus lanatus Thunb.) pollen for pollination under temperate conditions. Asian J. Plant Sci., 4: 44-49.

Loguercio, L.L., 2002. Pollen treatment in high osmotic potential: A simple tool for in vitro preservation and manipulation of viability in gametophytic populations. Braz. J. Plant Physiol., 14: $65-70$.

Mahmoodzadeh, H. and M. Bemani, 2008. Influence of salinity at early stage of flowering on the development of male gametophyte in canola (Brassica napus L.) cv. Symbol. Res. J. Environ. Sci., 2: 415-423.

Mehri, H., R. Mehri-Kamoun, A. Ben Dhiab and M. El Mahjoub, 2007. Adverse effects of insecticidal sprays on bloom onset, pollen germination and fruit set of three olive cultivars. Int. J. Agric. Res., 2: 102-114.

Picard, E., 1995. Historique des methods d'haplodiploidisation. Unisat, 95: 27-40.

Prom, L.K., 2007. Claviceps africana spore germination as influenced by components of sorghum floral extracts. Asian J. Plant Pathol., 1: 12-17.

Tamnet, R., E. Youmbi and G.T. Ndzomo, 2011. Optimization of maintaining factors of Senna spectabilis pollens: A bee species of Adamawa's flora (Cameroon). Asian J. Biotechnol., 3: 125-134.

Yang, J.S. and M. Endo, 2005. In vitro germination and viability of Dendranthema pollen. Asian J. Plant Sci., 4: 673-677.

Youmbi, E., M.T. Cerceau-Larrival, A.M. Verhille and M.C. Carbonnier-Jarreau, 1998. Morphologie et germination in vitro des pollens de Dacryodes edulis (Burseraceae). Grana, 37: 87-92. 